\title{
Fluorescent and Circular Dichroic Detection of Monosaccharides by Molecular Sensors: Bis[(Pyrrolyl)ethynyl]naphthyridine and Bis[(Indolyl)ethynyl]naphthyridine
}

\author{
Jim-Min Fang, ${ }^{*, \neq, \| l}$ Srinivasan Selvi,,$^{\ddagger}$ Jen-Hai Liao, ${ }^{\ddagger}$ Zdenek Slanina, ${ }^{\dagger, \neq}$ \\ Chao-Tsen Chen, ${ }^{*}, \neq$ and Pi-Tai Chou*,‡ \\ Contribution from the Department of Chemistry, National Taiwan University, \\ Taipei, 106, Taiwan and Genomic Research Center, Academia Sinica, Taipei, 115, Taiwan
}

Received October 26, 2003; E-mail: jmfang@ntu.edu.tw; zdenek@ims.ac.jp

\begin{abstract}
The push-pull conjugated molecules 2,7-bis-(1 H-pyrrol-2-yl)ethynyl-1,8-naphthyridine (BPN) and 2,7-bis ( $1 \mathrm{H}$-indol-2-yl)ethynyl-1,8-naphthyridine (BIN) adopting daad relays of proton donors $(d)$ and acceptors (a) form multiple hydrogen-bonding complexes with various monosaccharides that possess complementary adda sequences. Although the free BPN emits blue light at $\lambda_{\max }=475 \mathrm{~nm}$ in $\mathrm{CH}_{2} \mathrm{Cl}_{2}$, its complexation with octyl $\beta$-D-glucopyranoside gives green fluorescence at $\lambda_{\max }=535 \mathrm{~nm}$. The excellent photophysical properties make BPN a highly sensitive probe for monitoring glucopyranoside to a detection limit of $\sim 100 \mathrm{pM}$. On the other hand, the CD-silent BIN molecule binds with monosaccharides to form the CD-active multiple hydrogenbonding complexes, which exhibit the remarkable chirality dependent helicities consistent with the prediction by the ab initio approaches. On the basis of the similar daad cleft and hence the binding property, the fluorescence and CD absorption methods in BPN and BIN, respectively, are complementary, which, in combination with computational molecular modeling, not only give a detailed insight into the structures of the receptor-saccharide complexes in solution, but also differentiate octyl $\beta$-D-glucopyranoside from its enantiomer and other monosaccharides.
\end{abstract}

\section{Introduction}

Sensing of saccharides is essential in a variety of medical, diagnostic, and therapeutic contexts. ${ }^{1}$ Expeditious methods that distinguish D- and L-sugars are particularly crucial because the present enzymatic protocols ${ }^{2}$ cannot be exploited to detect unnatural sugars (e.g., L-glucose). Detection of the nonmetabolizable L-glucose can be applicable to the diagnosis of blood vessel damage. One approach to make an effective saccharide binding is to mimic the biotic carbohydrate recognition such as the protein-saccharide complex that comprises multiple hydrogenbonding interactions. ${ }^{3}$ Sensing of carbohydrates via the covalent formation of boronic esters relies on a well-defined geometry, ${ }^{4}$

Current address of Z. S.: Institute for Molecular Science, Myodaiji, Okazaki 444-8585, Japan.

$\doteqdot$ National Taiwan University.

"Genomic Research Center.

(1) For reviews, see: (a) Feizi, T.; Mulloy, B. Curr. Opin. Struct. Biol. 2001, 11, 585-586 and succeeding articles. (b) Williams, S. J.; Davies, G. J. Trends Biotechnol. 2001, 19, 356-362. (c) Roseman, S. J. Biol. Chem. 2001, 276, 41 527-41 542. (d) Dwek, R. A.; Butters, T. D. Chem. Rev. 2002, 102, 283-284 and succeeding articles. (e) Capila, I.; Linhardt, R. J. Angew. Chem., Int. Ed. 2002, 41, 390-412.

(2) Bodenner, D. L.; Eastman, R. C. Curr. Opin. Endocrinol. Diabetes 1995 , $21,72-77$.

(3) For reviews, see: (a) Aoyama, Y. In Comprehensive Supramolecular Chemistry, Atwood, J. L.; Davies, J. E. D.; MacNicol, D. D.; Vögtle, F. Eds.; Elsevier: Oxford, 1996, 2, 279-307. (b) Davis, A. P.; Wareham, R. S. Angew. Chem., Int. Ed. 1999, 38, 2978-2996.

(4) For reviews, see: (a) James, T. D.; Sandanayake, K. R. A. S.; Shinkai, S. Angew. Chem., Int. Ed. 1996, 35, 1911-1922. (b) James, T. D.; Shinkai, S. In Host-Guest Chemistry: Mimetic Approaches to Study Carbohydrate Recognition; Penadés, S., Ed.; Springer-Verlag: Berlin, 2002, 159-200.

10.1021/ja039237w CCC: $\$ 27.50$ @ 2004 American Chemical Society

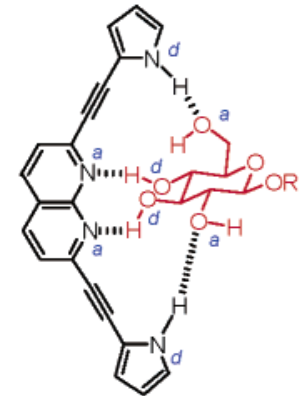

(a) BPN (1) / $\beta$-D-glucoside complex (b)

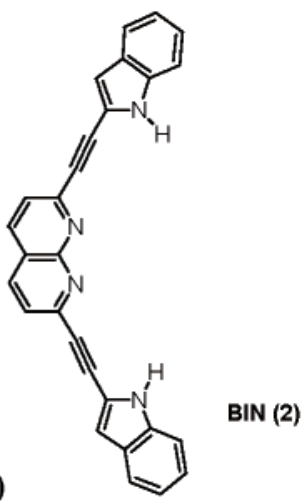

Figure 1. (a) Complexation of BPN with alkyl $\beta$-D-glucopyranoside via quadruple hydrogen bondings. (b) Structure of BIN with two indole rings in lieu of the pyrrole rings in BPN.

whereas the hydrogen-bonding recognition affords the superiority of the geometrical flexibility in complexation. Herein, we demonstrate two relatively simple molecular receptors, 2,7-bis(1H-pyrrol-2-yl)ethynyl-1,8-naphthyridine (BPN, Figure 1a) and 2,7-bis(1H-indol-2-yl)ethynyl-1,8-naphthyridine (BIN, Figure 1b), both of which possess a well-defined cleft with flexibility suited to an efficient multiple $\mathrm{H}$-bonds formation with various guest saccharides.

Both BPN and BIN possess a naphthyridine core moiety, in which two pyridinic nitrogen atoms act as the proton acceptors 
(aa). Attached to the $\mathrm{C} 2$ and $\mathrm{C} 7$ positions of naphthyridine are two identical arms, each of which consists of an ethynyl bridge terminated by pyrrole (in BPN) or indole (in BIN) moieties that function as the proton donors $(d d)$. The molecular framework for both BPN and BIN thus exhibits a unique property among the hydrogen-bonding type of artificial receptors, in which the conjugated daad arrays act intrinsically as the saccharide receptors as well as the sensing chromophores. ${ }^{5}$ The relay of hydroxyl groups in monosaccharides offers an adda motif complementary to the daad array of BPN (or BIN) to form a quadruple H-bonds complex.

Complexation of saccharides with a receptor is often detected by the ${ }^{1} \mathrm{H}$ NMR chemical-shift changes, ${ }^{6}$ though this method shows a limited sensitivity. Alternatively, one can use fluorescence spectroscopic methods to improve the detection sensitivity, ${ }^{7}$ as that shown in sensing octyl D-glucopyranoside by BPN. ${ }^{8}$ In this case, BPN provides an integral system for noncovalent recognition and direct visual detection of carbohydrate. From another approach, the induced circular dichroic (ICD) method has recently been explored for the saccharide detection by using electrostatic interactions as the major recognition motif, for example, in the cyclophane-phosphate, ${ }^{9}$ polypyridine, ${ }^{10}$ quinoline,${ }^{11}$ and porphyrin-type receptors ${ }^{12}$ bearing boronic acid units. Though BPN and BIN are CD-silent molecules, their bindings with chiral monosaccharide may come up with the CD-active complexes. Theoretically, the two pyrrole rings in BPN may show a $\mathrm{CD}$ exciton coupling effect ${ }^{13}$ to dictate the chirality of the BPN-saccharide complex. In lieu of the pyrrole rings, BIN containing the indole chromophores with absorption at longer

(5) (a) Bell, T. W.; Beckles, D. L.; Cragg, P. J.; Liu, J.; Maioriello, J.; Papoulis, A. T.; Santora, V. J. In Fluorescent Chemosensors for Ion and Molecular Recognition; Czarnik, A. W. Ed., Am. Chem. Soc. Washington DC, Chapter 7, 1993, 85-103. (b) Bell, Z. T.; Hou, W.; Luo, Y.; Drew, M. G. B.; Chapoteau, E.; Czech, B. P.; Kumar, A. Science 1995, 269, 671-674. (c) Lüning, U.; Kühl, C. Tetrahedron Lett. 1998, 39, 5735-5738. (d) Corbin P. S.; Zimmerman, S. C. J. Am. Chem. Soc. 2000, 122, 3779-3780.

(6) (a) Kobayashi, K.; Asakawa, Y.; Kato, Y.; Aoyama, Y. J. Am. Chem. Soc. 1992, 114, 10 307-10 313. (b) Bhattarai, K. M.; Bonar-Law, R. P.; Davis, A. P.; Murray, B. A. Chem. Commun. 1992, 752-754. (c) Liu, R.; Still, W. C. Tetrahedron Lett. 1993, 34, 2573-2576. (d) Huang, C.-Y.; Cabell, L. A.; Anslyn, E. V. J. Am. Chem. Soc. 1994, 116, 2778-2792. (e) Das, G.; Hamilton, A. D. J. Am. Chem. Soc. 1994, 116, 11 139-11 140. (f) Jiménez-Barbero, J.; Junquera, E.; Martín-Pastor, M.; Sharma, S.; Vicent C.; Penadés, S. J. Am. Chem. Soc. 1995, 117, 11 198-11 204. (g) Mizutani, T.; Kurahashi, K.; Murakami, T.; Matsumi, N.; Ogoshi, H. J. Am. Chem. Soc. 1997, 119, 8991-9001. (h) Davis, A. P.; Wareham, R. S. Angew. Chem., Int. Ed. Engl. 1998, 37, 2270-2273. (i) Inouye, M.; Takahashi, K.; Nakazumi, H. J. Am. Chem. Soc. 1999, 121, 341-345. (j) Bähr, A.; Felber, B.; Schneider, K.; Diederich, F. Helv. Chim. Acta 2000, 83, 13461376. (k) Bitta, J.; Kubik, S. Org. Lett. 2001, 3, 2637-2640. (1) Benito, J. M.; Gómez-García, M.; Blanco, J. L. J.; Mellet, C. O.; Fernández, J. M G. J. Org. Chem. 2001, 66, 1366-1372. (m) Mazik, M.; Radunz, W.; Sicking, W. Org. Lett. 2002, 4, 4579-4582.

(7) For general reviews, see: (a) Czarnik, A. W. Acc. Chem. Res. 1994, 27 302-308. (b) James, T. D.; Linnane, P.; Shinkai, S. Chem. Commun. 1996 281-288. (c) Fluorescence Spectroscopy, Imaging and Probes: New Tools in Chemical, Physical and Life Sciences; Kraayenhof, R.; Visser, A. J. W. G.; Gerritscen, H. C.; Eds.; Springer-Verlag: Berlin, 2002

(8) Liao, J.-H.; Chen, C.-T.; Chou, H.-C.; Cheng, C.-C.; Chou, P.-T.; Fang, J.-M.; Slanina, Z.; Chow, T. J. Org. Lett. 2002, 4, 3107-3110.

(9) (a) Kikuchi, Y.; Kobayashi, K.; Aoyama, Y. J. Am. Chem. Soc. 1992, 114 1351-1358. (b) Droz, A. S.; Neidlein, U.; Anderson, S.; Seiler, P.; Diederich, F. Helv. Chim. Acta 2001, 84, 2243-2289.

(10) (a) Tamaru, S.-i.; Yamamoto, M.; Shinkai, S.; Khasanov, A. B.; Bell, T W. Chem. Eur. J. 2001, 7, 5270-5276. (b) Tamaru, S.-i.; Shinkai, S. Khasanov, A. B.; Bell, T. W. Proc. Natl. Acad. Sci. 2002, 99, 4972-4976.

(11) (a) Mitzutani, T.; Kurahashi, T.; Murakami, T.; Matsumi, N.; Ogoshi, H. J. Am. Chem. Soc. 1997, 119, 8991-900. (b) Kim, Y.-H.; Hong, J.-I. Angew. Chem., Int. Ed. 2002, 41, 2947-2950.

(12) (a) Imada, T.; Kijima, H.; Takeuchi, M.; Shinkai, S. Tetrahedron Lett. 1995 36, 2093-2096. (b) Takeuchi, M.; Imada, T.; Shinkai, S. J. Am. Chem. Soc. 1996, 118, 10 658-10 659. (c) Sugasaki, A.; Sugiyasu, K.; Ikeda, M.; Takeuchi, M.; Shinkai, S. J. Am. Chem. Soc. 2001, 123, 10 239-10 244

(13) Nakanishi, K.; Berova, N.; Woody, R. W. Circular Dichroism: Principles and Applications; VCH: New York, 1994
Scheme 1. Synthesis of BPN (1) and BIN (2)

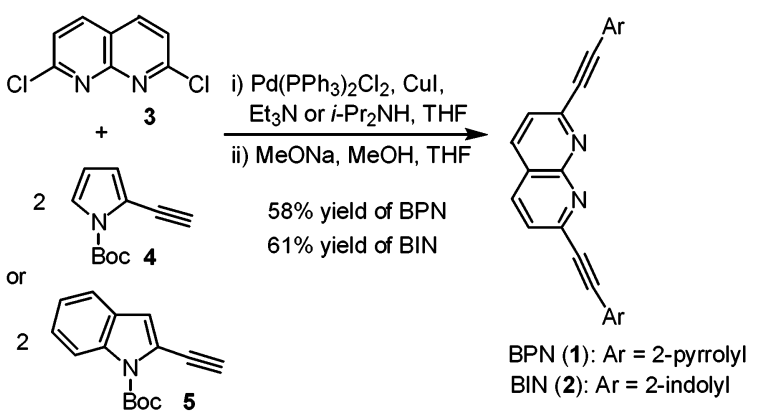

wavelengths may induce a more distinct $\mathrm{CD}$ exciton effect upon complexation with saccharide. We also anticipate that various saccharides can be differentiated by the corresponding $\mathrm{CD}$ spectra of their BIN complexes. Thus, the integration of UVvis, fluorescence and ICD titration methods, along with the assistance of molecular modeling, may gain detailed insights into the structures of the receptor-saccharide complexes in solution.

\section{Results and Discussion}

Synthesis and Characterization of Molecular Sensors BPN and BIN. The synthesis of BPN (Scheme 1) incorporated Sonogashira coupling reaction ${ }^{14}$ of 2,7-dichloro-1,8-naphthyridine (3) with 2 equiv of (1-tert-butoxycarbonyl-2-ethynyl)pyrrole (4). The Boc protective group was readily removed by stirring with $\mathrm{MeONa}$ at room temperature. The preparation of dichloronaphthyridine $\mathbf{3}$ was initiated by the condensation reaction of 2,6-diaminopyridine with malic acid according to the reported procedures. ${ }^{15}$ Sonogashira coupling reaction of 2-bromopyrrole-1-carboxylic acid tert-butyl ester with (trimethylsilyl)acetylene, followed by removal of the trimethylsilyl group with KF, afforded another starting material, ethynylpyrrole 4. By the similar procedures, (1-tert-butoxycarbonyl-2-ethynyl)indole (5), prepared from 1-tert-butoxycarbonyl-2-iodoindole and (trimethylsilyl)acetylene, was reacted with dichloronaphthyridine 3 to give BIN in $61 \%$ overall yield after removal of the Boc group.

The X-ray diffraction analysis of BPN indicated that the BPN molecule had an ideal $\mathrm{V}$-shaped cleft to provide as many as four hydrogen-bonding sites, in which the pyrrole and naphthyridine moieties function as the proton donors $(d)$ and acceptors $(a)$, respectively (Figure 2). ${ }^{16}$ The two pyrrole rings disposed their NHs as the preorganized inward conformation with a slight tilt toward opposite directions. The distance between two pyrrolyl nitrogen atoms was $12.2 \AA$, and the dihedral angles between the pyrrole and naphthyridine rings were $39.4^{\circ}$.

NMR Study of the Binding Modes of BPN with Octyl $\beta$-DGlucopyranoside. When a stock solution of $\mathrm{BPN}$ in $\mathrm{CDCl}_{3}$ $\left(2 \times 10^{-4} \mathrm{M}\right)$ was treated with 1 equiv of octyl $\beta$-Dglucopyranoside (as $0.02 \mathrm{M} \mathrm{CDCl}_{3}$ solution), the NHs on the pyrrole rings showed a large chemical-shift change $(\Delta \delta=1.4$ ppm). The glucoside counterpart also showed significant chemi-

(14) For a recent review, see: Tykwinski, R. R. Angew. Chem., Int. Ed. 2003, $42,1566-1568$

(15) (a) Newkome, G. R.; Garbis, S. J.; Majestic, V. K.; Fronczek, F. R.; Chiari, G. J. Org. Chem. 1981, 46, 833-839. (b) Ziessel, R.; Suffert, J.; Youinou, M.-T. J. Org. Chem. 1996, 61, 6535-6546.

(16) The crystallographic data of BPN have been deposited with the Cambridge Crystallographic Data Centre as no. CCDC 176324. 


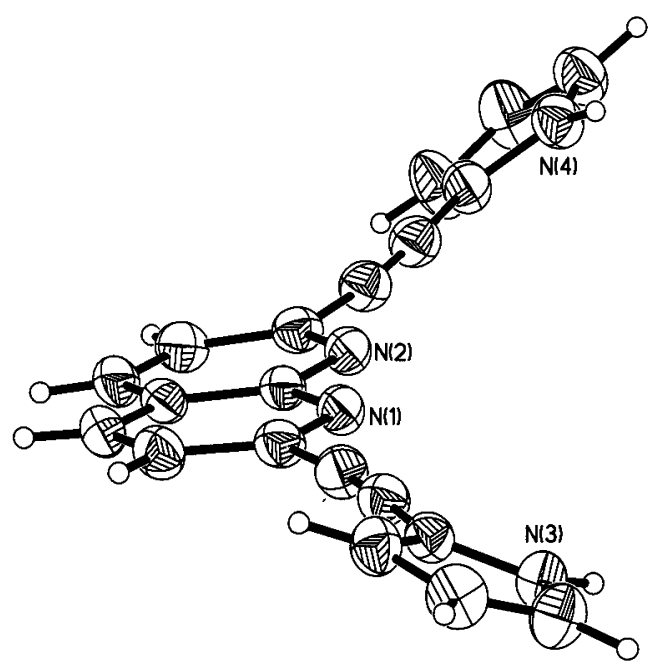

Figure 2. ORTEP drawing of BPN shows a V-shaped cleft.

cal-shift changes of hydroxyl protons (Figure 3). The 1:1 complexation of BPN with octyl $\beta$-D-glucopyranoside was supported by a continuous variation method (Job plot), ${ }^{17}$ in which the chemical-shift changes of pyrrole- $\mathrm{NH}$ as a function of saccharide concentrations were monitored. The binding constant of the BPN-saccharide complex, $K_{\mathrm{a}}=19800 \pm 810$ in $\mathrm{CDCl}_{3}$ solution at $300 \mathrm{~K}$, was determined by nonlinear regression analyses. ${ }^{17}$ The temperature dependent $(285-315 \mathrm{~K})$ ${ }^{1} \mathrm{H}$ NMR study indicated that the complex formation of BPN with octyl $\beta$-D-glucopyranoside was thermodynamically favored $\left(\Delta G_{300}=-24.7 \mathrm{~kJ} / \mathrm{mol}\right)$, in agreement with the proposed quadruple hydrogen-bonds formation (Figure 1a). A linear relationship was obtained by plotting $\ln K_{\mathrm{a}}$ as a function of $1 / T$ according to the equation: $\ln K_{\mathrm{a}}=-\Delta H / R T+\Delta S / R$. From the slope and intercept of the straight line, $\Delta H$ and $\Delta S$ were determined to be $-51.4 \mathrm{~kJ} / \mathrm{mol}$ and $-91.1 \mathrm{~J} / \mathrm{mol}$, respectively.

UV-Vis Spectra of the BPN and BIN Complexes with Octyl $\boldsymbol{\beta}$-D-Glucopyranoside. Upon adding octyl $\beta$-D-glucopyranoside, the $410-\mathrm{nm}$ free $\mathrm{BPN}$ band $(\epsilon=44700)$ in $\mathrm{CH}_{2} \mathrm{Cl}_{2}$ solution decreased significantly along with the growth of a new absorption band at $435 \mathrm{~nm}$ (Figure 4). An isosbestic point at $415 \mathrm{~nm}$ throughout the titration was attributed to the formation of BPN-saccharide hydrogen-bonding complexes in equilibrium with free BPN. The measured absorbance $\left[A_{0} /\left(A-A_{0}\right)\right]$ as a function of the inverse of the concentrations of octyl $\beta$-Dglucopyranoside fit a linear relationship, indicating the $1: 1$ stoichiometry of BPN-saccharide complex. ${ }^{18}$

The UV-vis spectrum of BIN in $\mathrm{CH}_{2} \mathrm{Cl}_{2}$ showed the absorption maxima at $319 \mathrm{~nm}(\epsilon=47700)$ and $413 \mathrm{~nm}(\epsilon=$ $71280)$ attributable to the indole and naphthyridine chromophores, respectively. As the amounts of octyl $\beta$-D-glucopyranoside increased, new absorption maxima at 325 and $440 \mathrm{~nm}$ appeared with a gradual increase of the absorbance, whereas the absorptions at 319 and $413 \mathrm{~nm}$ for the free BIN receptor decreased concomitantly (Figure 5). The occurrence of an isosbestic point at $426 \mathrm{~nm}$ throughout the titration supported the formation of the BIN-saccharide complex in equilibrium with free BIN.

(17) Connors, K. A. Binding Constants; Wiley: New York, 1987.

(18) Chou, P. T.; Wu, G. R.; Wei, C. Y.; Cheng, C. C.; Chang, C. P.; Hung, F T. J. Phys. Chem. B 2000, 104, 7818-7829. $A_{0}, F_{0}, A$, and $F$ denote respectively the absorbance and fluorescent intensity of free BPN, and solution after adding monosaccharides at a selective wavelength.
Fluorescence Titration of the BPN and BIN Complexes with Octyl $\boldsymbol{\beta}$-D-Glucopyranoside. Dual spectral features were observed in the fluorescence titration study of BPN with octyl $\beta$-D-glucopyranoside. The characteristic uncomplexed BPN emission band at $475 \mathrm{~nm}\left(\tau_{\mathrm{f}} \approx 1.25 \mathrm{~ns}\right)$ decreased, accompanied by the growth of a 535-nm ( $\left.\tau_{\mathrm{f}} \approx 0.95 \mathrm{~ns}\right)$ emission band. The results in combination with different excitation spectra between monitoring at e.g., 450 and $550 \mathrm{~nm}$ led us to conclude that dual fluorescence originates from different ground-state precursors, namely the uncomplexed BPN and BPN-saccharide complex, respectively (Figure 6). The free BPN emits a sky blue light, whereas its complexation with octyl $\beta$-D-glucopyranoside has a large Stokes' shift $(60 \mathrm{~nm})$ to emit a grass green light. The plot of $\left[F_{0} /\left(F-F_{0}\right)\right]$ at $535 \mathrm{~nm}$ versus the inverse of saccharide concentrations reconfirmed a $1: 1 \mathrm{BPN}$-saccharide complex. ${ }^{18}$ The fluorescence yield (i.e., the 535-nm band) for the complex of BPN and octyl $\beta$-D-glucopyranoside was measured to be as high as 0.25 in $\mathrm{CH}_{2} \mathrm{Cl}_{2}$. By selecting the excitation wavelength at $>460 \mathrm{~nm}$ where the absorbance was solely attributed to the BPN-saccharide complex, a detection limit as low as $\sim 100$ $\mathrm{pM}$ of octyl $\beta$-D-glucopyranoside could be achieved based on the nearly background (i.e., the uncomplexed BPN) free 535$\mathrm{nm}$ emission. The ratiometric fluorescence proved to be a reliable and ultrasensitive method for the real time detection of glucopyranoside.

The intrinsic conjugated daad type chromophore in BPN molecule is of key importance to account for the remarkable spectral differences. The acidity of pyrrole and basicity of naphthyridine could be enhanced at excited-state through the conjugated dual hydrogen-bonding effect. ${ }^{18}$ Upon complexation, the unusual push-pull daad relay would form multiple hydrogenbonds with saccharide and induce the $n, \pi$-electrons delocalization along the ethynyl bridge to account for a drastic alternation on the fluorescent property (Figure $7 \mathrm{a}$ ). ${ }^{19}$ Furthermore, rigidification upon formation of the BPN-saccharide complex might also contribute a certain role in enhancing the fluorescence as that shown in the previous studies on the bindings of ions ${ }^{20}$ and carbohydrates. ${ }^{19}$

For a comparison, the nonconjugated daad molecule of 2,7bis(3-hydroxy-3-methylbutynyl)-1,8-naphthyridine (BHN) was prepared (Figure 7b). The crystal structure of BHN also exhibits a cleft similar to BPN. The distance between the two oxygen atoms of $\mathrm{BHN}$ is $12.0 \AA$, close to that between the two pyrrolyl nitrogen atoms in BPN (12.2 $\AA$ ). Complexation of BHN with octyl $\beta$-D-glucopyranoside in $\mathrm{CDCl}_{3}$ solution was relatively weak $\left(K_{\mathrm{a}} \approx 1000 \mathrm{M}^{-1}\right.$ at $\left.300 \mathrm{~K}\right)$ as derived from the ${ }^{1} \mathrm{H}$ NMR titrations, in comparison with that of BPN complex $\left(K_{\mathrm{a}}=19800\right.$ $\left.\mathrm{M}^{-1}\right)$. The fluorescence intensity $\left(\lambda_{\max }=387 \mathrm{~nm}\right.$ in $\left.\mathrm{CH}_{2} \mathrm{Cl}_{2}\right)$ did increase upon complexation, albeit no significant spectral shift was observed. The enhanced fluorescence could be rationalized by the conformational rigidification, whereas the lack of a continuous push-pull $\pi$-system prohibited the multiple hydrogen-bonds induced charge-transfer effect.

(19) (a) Sandanayaka, K. R. A. S.; Nakashima, K.; Shinkai, S. Chem. Commun 1994, 1621-1622. (b) Takeuchi, M.; Yoda, S.; Imada, T.; Shinkai, S. Tetrahedron 1997, 53, 8335-8348.

(20) (a) McFarland, S. A.; Finney, N. S. J. Am. Chem. Soc. 2001, 123, 12601261. (b) Mello, J. V.; Finney, N. S. Angew. Chem., Int. Ed. 2001, 40, 1536-1538. (c) Choi, K.; Hamilton, A. D. Angew. Chem., Int. Ed. 2001 40, 3912-3915. (d) McFarland, S. A.; Finney, N. S. J. Am. Chem. Soc. 2002, 124, 1178-1179. 


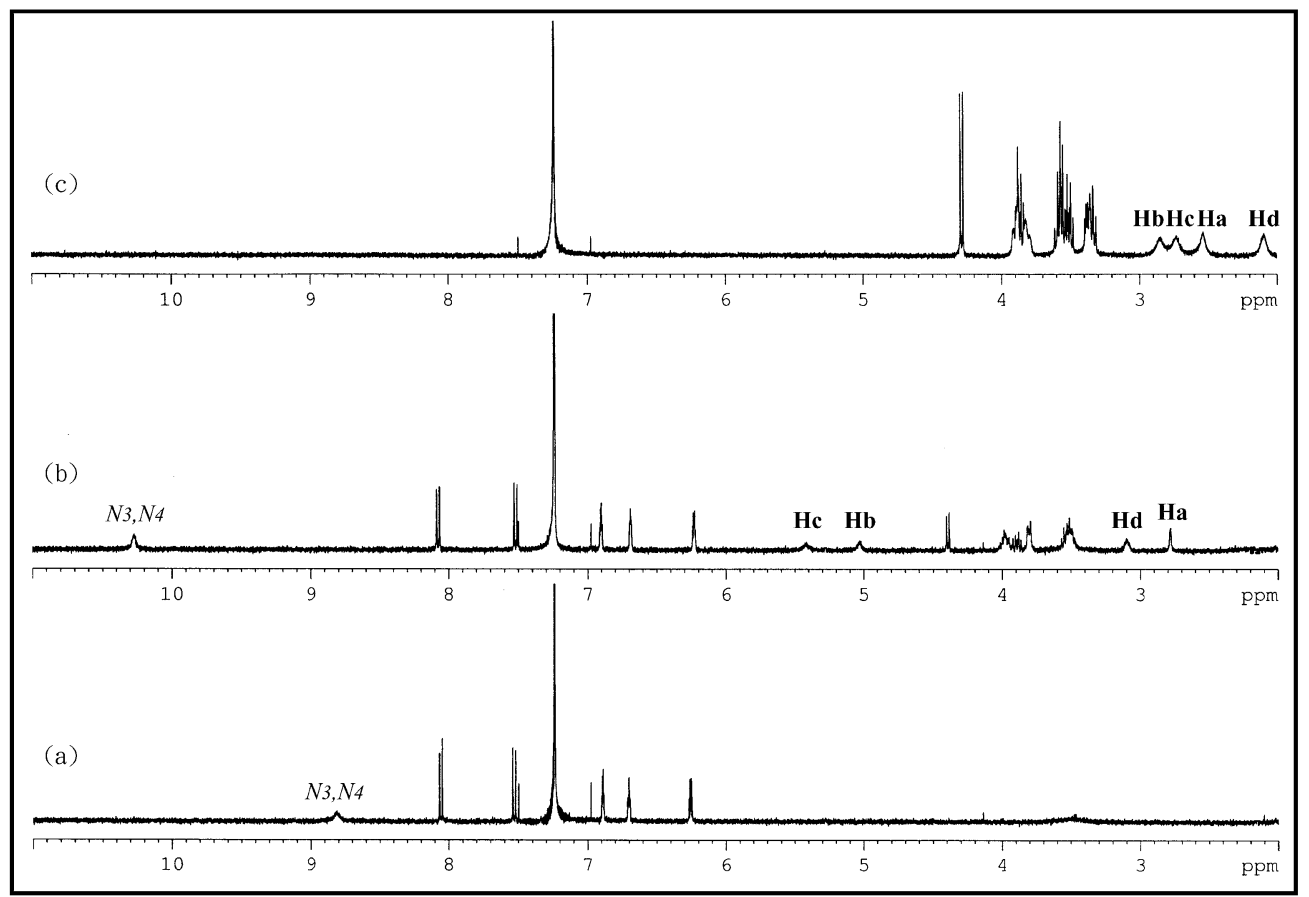

Figure 3. Induced ${ }^{1} \mathrm{H}$ NMR changes of $\mathrm{BPN}\left(5 \times 10^{-4} \mathrm{M}_{\text {in }} \mathrm{CDCl}_{3}, 300 \mathrm{~K}\right)$ on addition of octyl $\beta$-D-glucopyranoside: (a) free BPN, (b) BPN with octyl $\beta$-D-glucopyranoside (1 equiv), and (c) free octyl $\beta$-D-glucopyranoside $\left(1 \times 10^{-3} \mathrm{M}_{\text {in }} \mathrm{CDCl}_{3}, 300 \mathrm{~K}\right)$. The pyrrole protons of $\mathrm{BPN}$ are denoted as $\mathrm{N}_{3}, \mathrm{~N}_{4}$; the hydroxyl protons at the C-2, C-3, C-4, and C-6 positions of saccharide are denoted as $\mathrm{H}_{\mathrm{a}}, \mathrm{H}_{\mathrm{b}}, \mathrm{H}_{\mathrm{c}}$, and $\mathrm{H}_{\mathrm{d}}$, respectively.

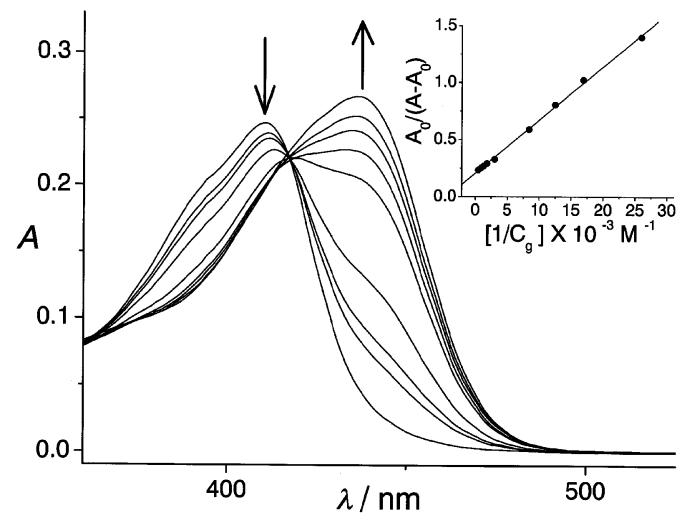

Figure 4. Absorption spectra of $\mathrm{BPN}\left(5.4 \times 10^{-6} \mathrm{M}\right)$ in $\mathrm{CH}_{2} \mathrm{Cl}_{2}$ by adding various concentrations $\left(C_{g}\right)$ of octyl $\beta$-D-glucopyranoside. Insert: The plot at $435 \mathrm{~nm}$ shows a linear relationship of $\left[A_{0} /\left(A-A_{0}\right)\right]$ vs $1 / C_{g}$, indicating the 1:1 stoichiometry of BPN-saccharide.

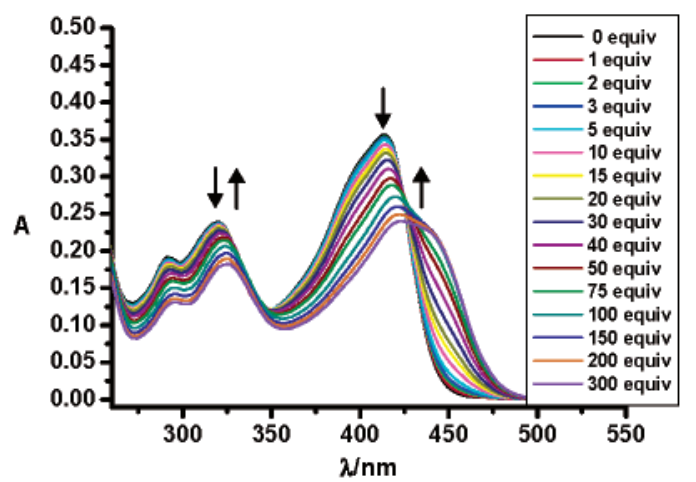

Figure 5. UV-vis titration of $\mathrm{BIN}\left(5 \times 10^{-6} \mathrm{M}\right)$ with octyl $\beta$-D-glucoside $\left(5 \times 10^{-3} \mathrm{M}\right)$ in $\mathrm{CH}_{2} \mathrm{Cl}_{2}$ solution.

Upon excitation at $413 \mathrm{~nm}, \mathrm{BIN}$ showed a fluorescence emission at $\lambda_{\max }=485 \mathrm{~nm}$ in $\mathrm{CH}_{2} \mathrm{Cl}_{2}$ solution. Unlike BPN or $\mathrm{BHN}$, the fluorescence intensity decreased on binding with octyl

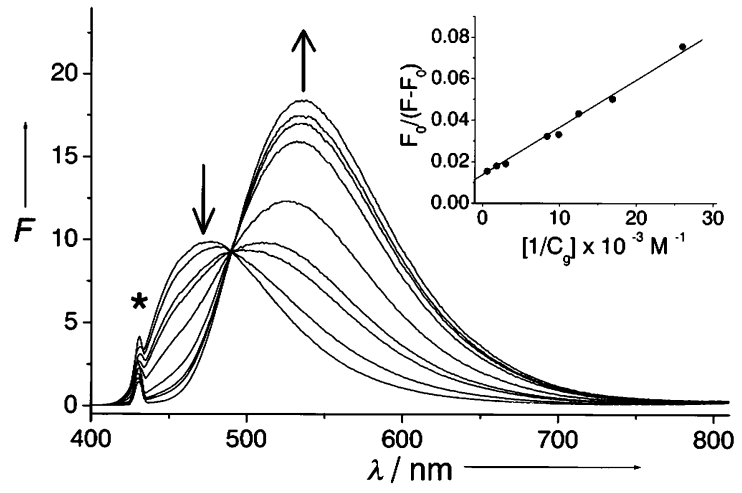

Figure 6. Fluorescence spectra of BPN $\left(1.2 \times 10^{-5} \mathrm{M}\right)$ in $\mathrm{CH}_{2} \mathrm{Cl}_{2}$ by adding various concentrations $\left(C_{g}\right)$ of octyl $\beta$-D-glucopyranoside. The fluorescence spectra $\left(\lambda_{\mathrm{ex}}=365 \mathrm{~nm}\right)$ show the growth of $535-\mathrm{nm}$ emission band on complexation, accompanied by decrease of $475-\mathrm{nm}$ band for uncomplexed BPN. * denotes Raleigh scattering. Insert: The plot at 535 $\mathrm{nm}$ shows a linear relationship of $\left[F_{0} /\left(F-F_{0}\right)\right]$ vs $1 / C_{g}$, indicating the $1: 1$ stoichiometry of BPN-saccharide complex.

$\beta$-D-glucopyranoside in different concentrations without obvious change of wavelength. The 1:1 stoichiometry and the binding constant $\left(K_{\mathrm{a}}=11700 \pm 1280 \mathrm{M}^{-1}\right)$ for the complexation of BIN with octyl $\beta$-D-glucopyranoside in $\mathrm{CH}_{2} \mathrm{Cl}_{2}$ solution were determined by the fluorescence titration method. Complexation of BIN with other glycosides also caused certain degrees of fluorescence quenching with a small red shift $(3-5 \mathrm{~nm})$. It appeared that the stronger the host-guest intermolecular hydrogen bondings induced a dominant quenching effect.

Comparison of the Binding Strengths of Different Saccharide Complexes. The examined alkyl monosaccharides 6-13 are either commercially available or prepared by known procedures. $^{21}$ The preferable 1:1 complexation of respective monosaccharide with BPN or BIN was similarly determined by absorption, fluorescence and ${ }^{1} \mathrm{H}$ NMR titration methods. The binding constants and free energy changes for various BPN and 
Table 1. Binding Constants and Free Energy Changes for BPN-Saccharide and BIN-Saccharide Complexes

\begin{tabular}{lcccc}
\hline \multicolumn{1}{c}{ alkyl saccharide } & $K_{\mathrm{a}} / \mathrm{M}^{-1}(\mathrm{BPN} \text { complex) })^{a}$ & $-\Delta \mathrm{G} / \mathrm{KJ} \mathrm{mol}^{-1}(\mathrm{BPN} \text { complex })^{b}$ & $K_{a} / \mathrm{M}^{-1}(\mathrm{BIN} \mathrm{complex})^{c}$ & $-\Delta \mathrm{G} / \mathrm{kJ} \mathrm{mol}{ }^{-1}(\mathrm{BIN} \mathrm{complex})^{b}$ \\
\hline$\beta$-D-glucoside 6 & $19800 \pm 810^{d}$ & 24.7 & $11700 \pm 1280$ & 23.1 \\
$\alpha$-D-glucoside 8 & $12600 \pm 450$ & 23.6 & $5690 \pm 560$ & 21.3 \\
$\alpha$-D-mannoside 9 & $25100 \pm 220$ & 25.3 & $13500 \pm 680$ & 23.4 \\
$\beta$-D-galactoside 10 & $6190 \pm 330^{e}$ & 21.8 & $7940 \pm 290$ & 22.1 \\
$\beta$-L-fucoside 11 & $1950 \pm 60$ & 18.9 & $2160 \pm 270$ & 18.9 \\
$\beta$-D-fructoside 12 & $490 \pm 7^{f}$ & 15.5 & $1540 \pm 100$ & 18.1 \\
$\beta$-D-riboside 13 & $605 \pm 30$ & 16.0 & & \\
\hline
\end{tabular}

${ }^{a}$ Derived by ${ }^{1} \mathrm{H}$ NMR titrations in $\mathrm{CDCl}_{3}$ solutions at $300 \mathrm{~K} .{ }^{b}-\Delta G=R T \ln K_{\mathrm{a}} \cdot{ }^{c}$ Derived by fluorescence titrations in $\mathrm{CH}_{2} \mathrm{Cl}_{2}$ solutions at $296 \mathrm{~K}$. The data represent the average values of two independent titrations. ${ }^{d}$ The binding constant in $\mathrm{CH}_{2} \mathrm{Cl}_{2}$ solution at $300 \mathrm{~K}$ was estimated to be $5500 \mathrm{M}^{-1}$ by fluorescence titrations, and $4800 \mathrm{M}^{-1}$ by UV-vis titrations. ${ }^{e}$ The binding constant in $\mathrm{CH}_{2} \mathrm{Cl}_{2}$ solution at $300 \mathrm{~K}$ was estimated to be $1600 \mathrm{M}^{-1}$ by absorption and fluorescence titrations. ${ }^{f}$ The binding constant in $\mathrm{CH}_{2} \mathrm{Cl}_{2}$ solution at $300 \mathrm{~K}$ was estimated to be $190 \mathrm{M}^{-1}$ by absorption and fluorescence titrations.
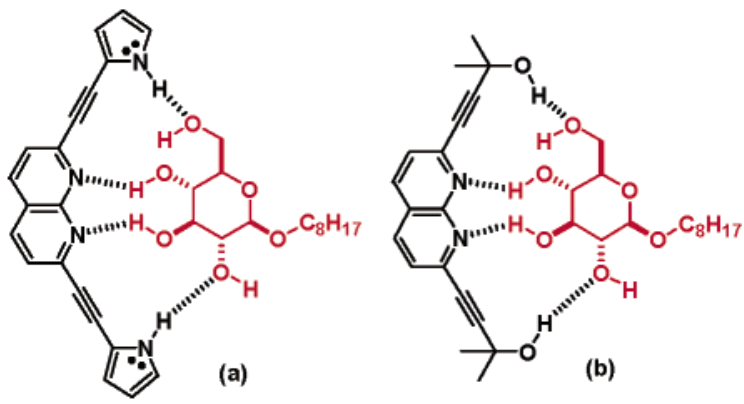

Figure 7. (a) A large Stokes' shift $(60 \mathrm{~nm})$ in the fluorescence spectrum of BPN-saccharide complex is attributed to the multiple hydrogen-bonds induced charge-transfer. (b) Complexation of BHN with saccharide does not show significant spectral shift because BHN lacks a continuous pushpull $\pi$-system to account for charge transfer.

BIN-saccharide complexes are collected in Table 1. The BIN and BPN showed the similar trend of binding strengths toward the examined monosaccharides, i.e., $\alpha$-D-mannopyranoside $>$ $\beta$-D-glucopyranoside $>(\alpha$-D-glucopyranoside, $\beta$-D-galactopyranoside) $\gg(\beta$-L-fucopyranoside, $\beta$-D-fructopyranoside, $\beta$-Dribofuranoside). It is thus reasonable to assume that BIN and BPN molecules behave similarly to bind with various monosaccharides.

While the only structural difference between octyl $\beta$-Dgalactopyranoside and octyl $\beta$-D-glucopyranoside is the spatial orientation of $4-\mathrm{OH}$, the binding constant for $\beta$-galactoside is much smaller than that of $\beta$-glucoside on complexation with either BPN or BIN. This binding selectivity is comparable to those reported in the literature. ${ }^{5,10 \mathrm{~b}}$ For octyl $\beta$-L-fucopyranoside in which one hydrogen bond is eliminated by modifying the $\mathrm{C}(6) \mathrm{CH}_{2} \mathrm{OH}$ to $\mathrm{CH}_{3}$ group, the binding constants with either $\mathrm{BPN}$ or BIN decrease dramatically. The binding of methyl $\beta$-Dribofuranoside with BPN is weak presumably because the complexation can at most accommodate three hydrogen bondings. The binding constant of octyl $\alpha$-D-glucopyranoside is less than that of $\beta$-anomer. It is assumed that a cis-gauche type hydrogen bonding occurs between the C-1 octoxy group and the $\mathrm{C}-2$ hydroxyl group in the $\alpha$-D-glucopyranoside, and thus renders a less efficient hydrogen bonding between the 2-OH group and the pyrrolyl (or indolyl) $\mathrm{NH}$ of BPN (or BIN). ${ }^{5 \mathrm{~m}, 10 \mathrm{~b}, 22}$ As supportive evidence, the ${ }^{1} \mathrm{H}$ NMR titration experiments indicated that the $2-\mathrm{OH}$ group of octyl $\alpha$-D-glucopyranoside

(21) (a) Nicolaou, K. C.; Hummel, C. W.; Nakada, M.; Shibayama, K.; Pitsinos, E. N.; Saimoti, H.; Mizuno, Y.; Baldenius, K.-U.; Smith, A. L. J. Am. Chem. Soc. 1993, 115, 7625-7635. (b) Zhang, X.; Kamiya, T.; Otsubo, N.; Ishida, H.; Kiso, M. J. Carbohydrate Chem. 1999, 18, 225-239. (c) Ferrières, V.; Bertho, J.; Plusquellec, D. Tetrahedron Lett. 1995, 36, 27492752. (d) Ferrières, V.; Benvegnu, T.; Lefeuvre, M.; Plusquellec, D. Mackenzie, G.; Watson, M. J.; Haley, J. A.; Goodby, J. W.; Pindak, R.; Durbin, M. K. J. Chem. Soc., Perkin Trans. 2 1999, 951-959.

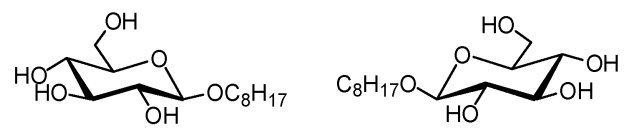

Octyl $\beta$-D-glucopyranoside (6) Octyl $\beta$-L-glucopyranoside (7)
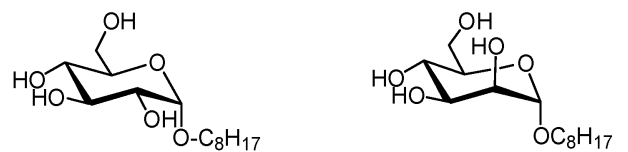

Octyl $\alpha$-D-glucopyranoside (8) Octyl $\alpha$-D-mannopyranoside (9)
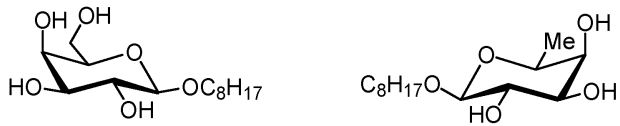

Octyl $\beta$-D-galactopyranoside (10) Octyl $\beta$-L-fucopyranoside (11)
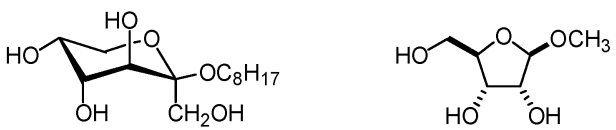

Octyl $\beta$-D-fructopyranoside (12) Methyl $\beta$-D-ribofuranoside (13)

showed a smaller chemical-shift change than the $\beta$-anomer on complexation with BPN. Among the examined saccharides, octyl $\alpha$-D-mannopyranoside exhibited the highest affinity toward BPN and BIN. The 2-OH group in mannoside was free from the intramolecular hydrogen bonding with octoxy group, and thus exerted a strong hydrogen bonding with the pyrrolyl (or indolyl) $\mathrm{NH}$ of BPN (or BIN). ${ }^{10 b, 22}$

Computational Molecular Modeling of BPN-Saccharide Complexes. Computations were carried out at ab initio levels using selected approximations implemented in the Gaussian program package. ${ }^{23}$ The complete geometry optimizations were performed with four increasingly more advanced methods. Three of them are ab initio Hatree-Fock (HF) methods, namely with the minimal STO-3G basis set (HF/STO-3G), with the $3-21 \mathrm{G}$

(22) (a) López de la Paz, M.; Ellis, G.; Pérez, M.; Perkins, J.; Jiménez-Barbero, J.; Vicent C. Eur. J. Org. Chem. 2002, 840-855. (b) Baggett, N.; Bukhari, M. A.; Foster, A. B.; Lehmann, J.; Webber, J. M. J. Chem. Soc. 1963 , 4157-4160. (c) Alonso, J. L.; Wilson, E. B. J. Am. Chem. Soc. 1980, 102, $1248-1251$.

(23) Frisch, M. J.; Trucks, G. W.; Schlegel, H. B.; Scuseria, G. E.; Robb, M. A.; Cheeseman, J. R.; Zakrzewski, V. G.; Montgomery, J. A., Jr.; Stratmann, R. E.; Burant, J. C.; Dapprich, S.; Millam, J. M.; Daniels, A. D.; Kudin, K. N.; Strain, M. C.; Farkas, O.; Tomasi, J.; Barone, V.; Cossi, M.; Cammi, R.; Mennucci, B.; Pomelli, C.; Adamo, C.; Clifford, S.; Ochterski, J.; Petersson, G. A.; Ayala, P. Y.; Cui, Q.; Morokuma, K.; Malick, D. K; Rabuck, A. D.; Raghavachari, K.; Foresman, J. B.; Cioslowski, J.; Ortiz, J. V.; Stefanov, B. B.; Liu, G.; Liashenko, A.; Piskorz, P.; Komaromi, I.; Gomperts, R.; Martin, R. L.; Fox, D. J.; Keith, T.; Al-Laham, M. A.; Peng, C. Y.; Nanayakkara, A.; Gonzalez, C.; Challacombe, M.; Gill, P. M. W.; Johnson, B.; Chen, W.; Wong, M. W.; Andres, J. L.; Gonzalez, C.; HeadGordon, M.; Replogle, E. S.; Pople, J. A. GAUSSIAN 98, Revision A.7, Gaussian, Inc., Pittsburgh, PA, 1998. 
(a)

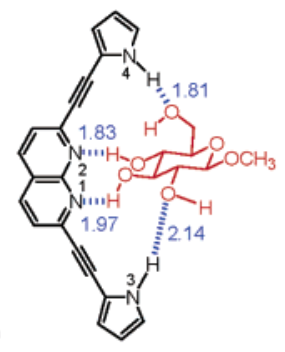

(b)

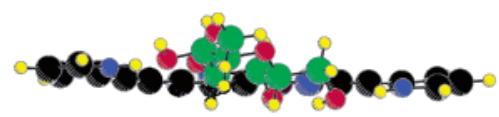

(d)

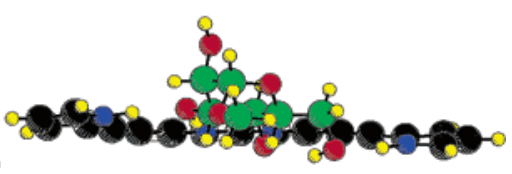

Figure 8. (a) Scheme for the geometrically optimized BPN/methyl $\beta$-D-glucopyranoside complex derived by the B3LYP/6-31G** method. The distances $(\AA)$ of the hydrogen bonds are shown. (b) The geometrically optimized BPN/ $\beta$-D-glucopyranoside complex that shows a $P$-helicity with a clockwise twist of the BPN backbone. (c) The geometrically optimized BPN $/ \beta$-D-galactoside complex with the $M$-helicity. (d) The geometrically optimized BPN/ $\alpha$-Dmannoside complex with the $P$-helicity. Black balls: carbon atoms in BIN; green balls: carbon atoms in saccharide; yellow balls: hydrogen atoms; blue balls: nitrogen atoms, and red balls: oxygen atoms.

Table 2. Computed Lengths of Hydrogen Bonds (in $\AA$ ) and the Dimerization Energies $\left(E_{\text {dim, }}\right.$ in $\left.\mathrm{kJ} / \mathrm{mol}\right)$ for the Complex of BPN with Methyl $\beta$-D-Glucopyranoside, Methyl $\beta$-D-Galactopyranoside and Methyl $\alpha$-D-Mannopyranoside ${ }^{a}$

\begin{tabular}{lccccc}
\hline methyl saccharide & $\mathrm{N}(1)-\mathrm{HO}(3)$ & $\mathrm{N}(2)-\mathrm{HO}(4)$ & $\mathrm{N}(3) \mathrm{H}-\mathrm{O}(2)$ & $\mathrm{N}(4) \mathrm{H}-\mathrm{O}(6)$ & $E_{\text {dim }}$ \\
\hline$\beta$-D-glucoside & 1.970 & 1.827 & 2.140 & 1.813 & -149.9 \\
$\beta$-D-galactoside & 2.098 & 1.840 & 2.141 & 1.826 & -146.9 \\
$\alpha$-D-mannoside & 2.165 & 1.842 & 1.951 & 1.809 & -135.2 \\
\hline
\end{tabular}

${ }^{a}$ Molecular calculations were conducted with B3LYP/6-31G** method.

basis set $(\mathrm{HF} / 3-21 \mathrm{G})$, and with the $6-31 \mathrm{G}^{* *}$ basis set $(\mathrm{HF} /$ 6-31G**). Moreover, density functional theory was also applied, namely Becke's three parameter functional with the nonlocal Lee-Yang-Parr correlation functional in the standard 6-31G** basis set (B3LYP/6-31G**), as the approach, in contrast to the HF treatments, can include correlation energy (with reasonable computational demands). In evaluations of the dimerization energies $\left(E_{\mathrm{dim}}\right)$, the basis set superposition error (BSSE) was estimated using the approximative counterpoise method.

The molecular modeling of BPN-saccharide complexes implied the importance of multiple hydrogen-bonds formation as well as the geometrical fitness to accommodate each hydrogen bond (Figure 8a). All calculated $\mathrm{OH} \cdots \mathrm{N}$ and $\mathrm{NH} \cdot \cdots \mathrm{O}$ distances are significantly shorter than the sum of van der Waals radii of $\mathrm{H}$ and $\mathrm{N}(2.7 \AA)$ and $\mathrm{H}$ and $\mathrm{O}(2.6 \AA)$. At the highest level of computations, B3LYP/6-31G**, the computed lengths of hydrogen bonds and the dimerization energies for the complexes of BPN with methyl $\beta$-D-glucopyranoside, methyl $\beta$-D-galactopyranoside and methyl $\alpha$-D-mannopyranoside are listed in Table 2. The most prominent hydrogen bonding occurs between C-6 oxygen atom and the pyrrolyl NH. This computation result supports that the binding of octyl $\beta$-L-fucopyranoside with BPN is weak due to a lack of this hydrogen bond. In comparison with the galactose complex, all the four computed hydrogenbond distances are bit shorter and the computed depth of the energy minimum is slightly deeper in the glucose complex. The mannoside complex shows somewhat a shallower minimum at the B3LYP/6-31G** level, even the hydrogen bond between $\mathrm{N}(3) \mathrm{H}$ and $\mathrm{O}(2)$ is short. The relative stabilities of the three species could be still influenced by two factors, entropy and environmental effects (e.g., solvent and temperature), not considered in our calculations of the potential energy changes in gas phase. Moreover, the dimerization energies should be somewhat reduced by addition of the vibrational zero-point energies.

Though BPN is an achiral molecule, it is expected to form chiral complexes with chiral saccharides. On the basis of the B3LYP/6-31G** computation, the complex of BPN with $\beta$-Dglucopyranoside exhibited a $P$-helicity ${ }^{24}$ with clockwise twist of the BPN backbone, i.e., the upward pyrrole on the left-hand side moving clockwise along the ethynyl-naphyridine-ethynyl backbone to the downward pyrrole on the right-hand side (Figure $8 \mathrm{~b})$. Although $\beta$-D-galactopyranoside differed from $\beta$-D-glucopyranoside simply by the orientation of the 4-OH group, the molecular model of BPN $/ \beta$-D-galactoside complex indicated a counterclockwise twist of backbone ( $M$-helicity, Figure $8 \mathrm{c}$ ) with the upward pyrrole on the right-hand side and the downward pyrrole on the left-hand side. The molecular modeling also predicted that the complex of BPN with $\alpha$-D-mannopyranoside would have a $P$-helicity (Figure $8 \mathrm{~d}$ ) as that of $\mathrm{BPN} / \beta$-Dglucoside complex.

Application of CD Spectroscopy to Distinguish Different BIN-Saccharide Complexes. We conducted the CD measurements for the complexation of BIN with several octyl monosaccharides (Figure 9) in order to substantiate the above structural modeling. The results turned out to be in good agreement with the prediction by ab initio computations. In lieu of the pyrrole rings in $\mathrm{BPN}$, the $\mathrm{BIN}$ molecule containing two indole rings would induce a larger $\mathrm{CD}$ exciton coupling effect on binding with chiral saccharides.

Addition of octyl $\beta$-D-glucopyranoside to BIN produced a positive ICD signal at about $442 \mathrm{~nm}$, as well as an exciton couplet at about $325 \mathrm{~nm}$ (intersection point) with the first negative and second positive Cotton effects at $344 \mathrm{~nm}([\theta]=$ $-16900)$ and $317 \mathrm{~nm}([\theta]=500)$, respectively (Table 3$)$. As the two indole rings could be brought into an inward conformation upon binding with a chairlike pyranoside, the exciton coupling of the two indole chromophores $\left(\lambda_{\mathrm{abs}} \approx 325 \mathrm{~nm}\right)$ would reflect the helicity of the BIN backbone, i.e., a negative Cotton effect for the $P$-helicity. On the other hand, the complex of BIN and octyl $\beta$-L-glucopyranoside (the enantiomer of octyl $\beta$-D-

(24) Eliel, E. L.; Wilen, S. H.; Mander, L. N. Stereochemistry of Organic Compounds; Wiley: New York, 1994; pp 1012 and 1200. 


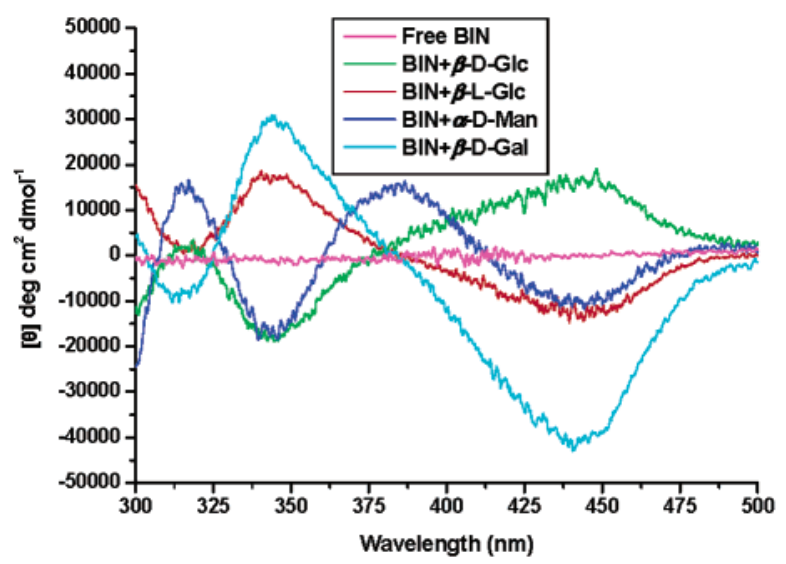

Figure 9. $\mathrm{CD}$ spectra of $\mathrm{BIN}\left(1 \times 10^{-5} \mathrm{M}\right)$ and its complexation with saccharides $\left(2 \times 10^{-2} \mathrm{M}\right)$ in $\mathrm{CH}_{2} \mathrm{Cl}_{2}$ solutions.

Table 3. CD Spectral Data for BIN/Octyl Saccharide Complexes in $\mathrm{CH}_{2} \mathrm{Cl}_{2}$ Solutions ${ }^{a}$

\begin{tabular}{llc}
\hline \multicolumn{1}{c}{ BIN/saccharide } & \multicolumn{1}{c}{$\lambda_{\text {max }} / \mathrm{nm}\left([\theta] / \mathrm{deg} \mathrm{cm}^{2} \mathrm{dmol}^{-1}\right)$} & $\Delta[\theta]^{b}$ \\
\hline$\beta$-D-glucoside 6 & $442(10100), 344(-16900), 317(500)$ & -17400 \\
$\beta$-L-glucoside 7 & $442(-10100), 344(17700), 317(300)$ & +17400 \\
$\alpha$-D-mannoside 9 & $442(-10900), 344(-17400), 317(1500)$ & -18900 \\
$\beta$-D-galactoside 10 & $442(-41300), 344(30600), 317(-9500)$ & +40100 \\
\hline
\end{tabular}

${ }^{a}$ The $\mathrm{CH}_{2} \mathrm{Cl}_{2}$ solution of $\mathrm{BIN}\left(1 \times 10^{-5} \mathrm{M}\right)$ and saccharide $\left(2 \times 10^{-2}\right.$ M) was used. ${ }^{b}$ The difference of absorptions at two extremes of the exciton couplet. Plus value refers to positive exciton coupling, whereas negative value refers to negative exciton coupling.

glucopyranoside) furnished a reversed ICD band and a positive exciton couplet with the same amplitudes. These two CD curves looked like mirror images of each other. Thus, D- and Lsaccharides can be easily distinguished from their BIN complexes by using a CD method. The positive Cotton effect at $\lambda_{\max } \approx 344 \mathrm{~nm}$ accounts for the $M$-helical structure of BIN/ $\beta$-D-galactoside complex, whereas the negative Cotton effect for the BIN/ $\alpha$-D-mannoside complex indicated its $P$-helicity that is also supported by computation.

Conclusion. Our results demonstrate the selective affinity and ultrasensitivity for probing the BPN $/ \beta$-glucoside complex. Visual change of free BPN (cyanic color) in $\mathrm{CH}_{2} \mathrm{Cl}_{2}$ to green color upon addition of octyl glucopyranoside was obvious. Our study evokes a novel concept of complementary proton donor $(d)$ and acceptor $(a)$ relays in designing molecular receptors of carbohydrates. The glycopyranoside is considered as an adda substrate to bind efficiently with the daad receptors BPN and BIN via multiple hydrogen bondings. This binding mode is supported by NMR, absorption, and fluorescence spectral analyses. The $\mathrm{CD}$ spectra and molecular computations give a consistent picture of the three-dimensional structures of complexes in solutions, which is a problem not easily tackled by X-ray diffraction and other methods. In combination of the high fluorescence sensitivity of BPN and the $\mathrm{CD}$ exciton effect with BIN complexation, sensing of $\beta$-D-glucopyranoside at low concentration $(\sim 100 \mathrm{pM})$ is achieved, and the differentiation of $\beta$-D-glucopyranoside from its enantiomer and other monosaccharides is realized. This study can be advanced by using the fluorescence detected circular dichroism (FDCD), ${ }^{25}$ or by designing the water-soluble ana-

(25) (a) Dong, J.-G.; Wada, A.; Takakuwa, T.; Berova, N.; Nakanishi, K. J. Am. Chem. Soc. 1997, 119, 12 024-12 025. (b) Nehira, T.; Parish, C. A. Jockusch, S.; Turro, N. J.; Nakanishi, K.; Berova, N. J. Am. Chem. Soc. 1999, 121, 8681-8691. logues of BPN/BIN receptors for direct sensing of sugars without prior derivatization to alkyl saccharides. We are currently engaged in this research work.

\section{Experimental Section}

General. All reactions requiring anhydrous conditions were conducted in flame-dried apparatus under an inert atmosphere using standard techniques. Syringes and needles for the transfer of reagents were dried at $100{ }^{\circ} \mathrm{C}$ and allowed to cool in a desiccator over $\mathrm{P}_{2} \mathrm{O}_{5}$ before use. All the reagents and solvents were reagent grade and were used without further purification unless otherwise specified. Ethers were distilled from sodium benzophenone ketyl; (chlorinated) hydrocarbons, and amines from $\mathrm{CaH}_{2}$. Reactions were monitored by TLC using aluminum plates precoated with a $0.25 \mathrm{~mm}$ layer of silica gel containing a fluorescent indicator (Merck Art. 5544). Kieselgel $60(40-63 \mu \mathrm{m})$ and neutral aluminum oxide (Acros, 50-200 $\mu \mathrm{m}$ ) were used for column chromatography. Melting points are uncorrected. Chemical shifts $(\delta)$ are given in parts per million $(\mathrm{ppm})$ relative to $\delta_{\mathrm{H}} 7.24 / \delta_{\mathrm{C}} 77.0$ (central line of t) for $\mathrm{CHCl}_{3} / \mathrm{CDCl}_{3}$ and $\delta_{\mathrm{H}} 2.49(\mathrm{~m}) / \delta_{\mathrm{C}} 39.5(\mathrm{~m})$ for DMSO$d_{6}$. The splitting patterns are reported as $\mathrm{s}$ (singlet), d (doublet), $\mathrm{t}$ (triplet), and multiplet (m). Coupling constants $(J)$ are given in $\mathrm{Hz}$. Distortionless enhancement polarization transfer (DEPT) spectra were taken to determine the types of carbon signals.

2,7-Bis-(1H-pyrrol-2-yl)ethynyl-1,8-naphthyridine (BPN, 1). To a suspension of 2,7-dichloro-1,8-naphthyridine $(\mathbf{3}, 137 \mathrm{mg}, 0.72 \mathrm{mmol})$ in anhydrous THF $(2 \mathrm{~mL})$ was added triethylamine $(1.38 \mathrm{~mL})$, $\mathrm{Pd}\left(\mathrm{PPh}_{3}\right)_{2} \mathrm{Cl}_{2}(20.1 \mathrm{mg})$ and $\mathrm{CuI}(11 \mathrm{mg})$ under argon. After stirring at room temperature for $10 \mathrm{~min}$, 2-ethynylpyrrole-1-carboxylic acid tertbutyl ester $(4,276 \mathrm{mg}, 1.45 \mathrm{mmol})$ in anhydrous THF $(10 \mathrm{~mL})$ was added slowly. The resulting red solution was stirred at room temperature for $40 \mathrm{~h}$. The reaction mixture was passed through a short plug of diatomaceous earth, and washed with EtOAc. The combined organic phase was evaporated to dryness under reduced pressure to give pale brown solid. After washing with hot hexane the crude product was recrystallized from EtOAc/hexane to give 2,7-bis-(1-tert-butoxycarbonylpyrrol-2-yl)ethynyl-1,8-naphthyridine (BPN-Boc, $189 \mathrm{mg}$ ). The filtrate was concentrated to dryness, and followed the previous procedure to give the second crop $(97 \mathrm{mg})$. Total yield: $78 \%$.

To a solution of BPN-Boc (100 mg, $0.197 \mathrm{mmol})$ in anhydrous THF $(5 \mathrm{~mL})$ was added $\mathrm{MeONa}$ ( $63.8 \mathrm{mg}, 6$ equiv) in anhydrous $\mathrm{MeOH}(5$ $\mathrm{mL}$ ). The resulting mixture was allowed to stir at room temperature for $1 \mathrm{~h}$. After evaporation to dryness the residue was treated with water $(30 \mathrm{~mL})$ and $\mathrm{CH}_{2} \mathrm{Cl}_{2}(50 \mathrm{~mL})$. The mixture was neutralized with $1 \mathrm{~N}$ $\mathrm{HCl}$ aqueous solution. The lower layer was separated, and the aqueous layer was extracted with another portion of $\mathrm{CH}_{2} \mathrm{Cl}_{2}(30 \mathrm{~mL})$. The combined organic phase was dried $\left(\mathrm{Na}_{2} \mathrm{SO}_{4}\right)$, filtered, and evaporated to dryness under reduced pressure. The crude product was purified by column chromatography with elution of $2.5-10 \% \mathrm{MeOH} / \mathrm{CH}_{2} \mathrm{Cl}_{2}$ to give $\mathrm{BPN}$ (45 mg, 74\%). Orange crystal, $\mathrm{mp}>300{ }^{\circ} \mathrm{C}$ (darken above $\left.160{ }^{\circ} \mathrm{C}\right)$; TLC $\left(\mathrm{MeOH} / \mathrm{CH}_{2} \mathrm{Cl}_{2}(9: 1)\right) R_{f}=0.57$; IR (KBr) 3215, 2196, $1593 \mathrm{~cm}^{-1} ;{ }^{1} \mathrm{H}$ NMR (DMSO- $\left.d_{6}, 400 \mathrm{MHz}\right) \delta 11.86(2 \mathrm{H}, \mathrm{s}), 8.43(2$ $\mathrm{H}, \mathrm{d}, J=8.2 \mathrm{~Hz}), 7.66(2 \mathrm{H}, \mathrm{d}, J=8.2 \mathrm{~Hz}), 7.00(2 \mathrm{H}, \mathrm{m}), 6.67(2$ $\mathrm{H}, \mathrm{m}), 6.19(2 \mathrm{H}, \mathrm{m}) ;{ }^{13} \mathrm{C} \mathrm{NMR}\left(\mathrm{CD}_{3} \mathrm{OD}, 100 \mathrm{MHz}\right) \delta 156.5(\mathrm{C})$, $149.0(2 \times \mathrm{C}), 138.8(2 \times \mathrm{CH}), 125.9(2 \times \mathrm{CH}), 123.1(2 \times \mathrm{CH})$, $122.1(\mathrm{C}), 118.5(2 \times \mathrm{CH}), 112.2(2 \times \mathrm{C}), 110.4(2 \times \mathrm{CH}), 91.6(2 \times$ C), $88.5(2 \times \mathrm{C})$; FAB-MS $\mathrm{m} / \mathrm{z}$ (rel intensity) $309\left(\mathrm{M}^{+}+1,43 \%\right)$; HRMS calcd for $\mathrm{C}_{20} \mathrm{H}_{13} \mathrm{~N}_{4}\left(\mathrm{M}^{+}+1\right)$ 309.1140, found 309.1141. Anal. Calcd for $\mathrm{C}_{20} \mathrm{H}_{12} \mathrm{~N}_{4}$ : C, 77.91; H, 3.92; N, 18.17. Found: C, 77.60; H, $4.08 ; \mathrm{N}, 18.07$.

2,7-Bis-(1H-indole-2-yl)ethynyl-1,8-naphthyridine (BIN, 2). By a procedure similar to that for BPN-Boc, Sonogashira coupling reaction of 2,7-dichloronaphthyridine (300 mg, $1.5 \mathrm{mmol}$ ) with 2-ethynylindole1-carboxylic acid tert-butyl ester $(\mathbf{5}, 725 \mathrm{mg}, 3 \mathrm{mmol})$ using $\mathrm{Pd}\left(\mathrm{PPh}_{3}\right)_{2^{-}}$ $\mathrm{Cl}_{2}$, CuI and $i$ - $\mathrm{Pr}_{2} \mathrm{NH}$ in THF gave 2,7-bis-[1-(tert-butoxycarbonyl)indole-2-yl] ethynyl-1,8-naphthyridine (BIN-Boc, $630 \mathrm{mg}, 69 \%$ ). The Boc group was removed by $\mathrm{MeONa}$ in $\mathrm{MeOH}$, by a procedure similar 
to that for BPN, to give BIN in $89 \%$ yield. Pale yellow solid, mp 278 ${ }^{\circ} \mathrm{C}$ (decomp.). TLC (EtOAc/hexane (4:6)) $R_{f}=0.53$. IR (KBr) 3435, 2213, $1602 \mathrm{~cm}^{-1} ;{ }^{1} \mathrm{H}$ NMR $\left(\mathrm{CDCl}_{3}, 400 \mathrm{MHz}\right) \delta 11.97(\mathrm{~s}, 2 \mathrm{NH})$, $8.56(\mathrm{~d}, J=8.2 \mathrm{~Hz}, 2 \mathrm{H}), 7.84(\mathrm{~d}, J=8.2 \mathrm{~Hz}, 2 \mathrm{H}), 7.62(\mathrm{~d}, J=8.0$ $\mathrm{Hz}, 2 \mathrm{H}), 7.40(\mathrm{~d}, J=8.2 \mathrm{~Hz}, 2 \mathrm{H}), 7.24(\mathrm{t}, J=7.6 \mathrm{~Hz}, 2 \mathrm{H}), 7.08(\mathrm{t}$, $J=7.7 \mathrm{~Hz}, 2 \mathrm{H}), 7.06(\mathrm{~s}, 2 \mathrm{H}) ;{ }^{13} \mathrm{C} \mathrm{NMR}\left(\mathrm{CDCl}_{3}, 100 \mathrm{MHz}\right) \delta 155.0$ $(2 \times \mathrm{C}), 146.0(2 \times \mathrm{C}), 138.1(2 \times \mathrm{CH}), 136.8(\mathrm{C}), 126.9(\mathrm{C}), 125.2$ $(2 \times \mathrm{CH}), 123.7(2 \times \mathrm{CH}), 121.3(2 \times \mathrm{C}), 120.7(2 \times \mathrm{CH}), 120(2 \times$ $\mathrm{CH}), 116.5(2 \times \mathrm{C}), 111.4(2 \times \mathrm{CH}), 110.1(2 \times \mathrm{CH}), 92.0(2 \times \mathrm{C})$, $84.9(2 \times \mathrm{C})$; HR-FAB-MS calcd for $\mathrm{C}_{28} \mathrm{H}_{17} \mathrm{~N}_{4}$ : 409.15; found: $\mathrm{m} / \mathrm{z}$ $409.15\left(\mathrm{M}^{+}+\mathrm{H}\right)$.

${ }^{1} \mathrm{H}$ NMR Titration Studies. ${ }^{1} \mathrm{H}$ NMR spectra were measured on Brucker Avance-400 NMR spectrometer. A typical experiment was performed as follows. A solution of BPN in $\mathrm{CDCl}_{3}$ was prepared $(2 \times$ $10^{-4} \mathrm{M}$ ), and a $0.4-\mathrm{mL}$ portion was transferred to a 5-mm NMR tube. A small aliquot of the $\mathrm{CDCl}_{3}$ solution $(0.02 \mathrm{M})$ containing the examined saccharide was introduced to the BPN solution in an incremental fashion, and their corresponding spectra were recorded. The chemical shift of $N_{3}, N_{4}-\mathrm{H}$ of BPN was monitored as a function of saccharide concentrations. Nonlinear regression analyses were used to determine the binding constants.

UV-Vis Titration Studies. UV-vis spectra were obtained using Hewlett-Packard-8453 spectrophotometer. A typical experiment was performed as follows.

The stock solutions of BIN $\left(1 \times 10^{-6} \mathrm{M}\right)$ and octyl saccharides $\left(5 \times 10^{-3} \mathrm{M}\right)$ were prepared by using spectroscopic grade dichloromethane. The BIN solutions in the range of $1 \times 10^{-6} \mathrm{M}$ to $5 \times 10^{-6}$ $\mathrm{M}$ exhibited a linear dependence of absorbance. The absorption spectrum of BIN stock solution $(2 \mathrm{~mL})$ in a quartz cell $(1 \mathrm{~cm}$ length) was recorded, and then the stock solution of alkyl saccharide was introduced in an incremental fashion $(1,2,4,8,16,25,50,100,150$, 200, 250, 300, and $400 \mu \mathrm{L} ; 1 \mu \mathrm{L}$ corresponds to 2.5 equiv) and their corresponding UV-vis curves were recorded.

On the basis of 1:1 stoichiometry of complex, the relationship between the measured absorbance $A$ as a function of the added saccharide concentration, $C_{g}$, can be expressed by $A_{0} / A-A_{0}=$ $\left(\epsilon_{M} / \epsilon_{C}-\epsilon_{M}\right)\left[1 / K_{a} C_{g}+1\right]$, where $\epsilon_{M}$ and $\epsilon_{C}$ are molar extinction coefficients of the BPN (or BIN) monomer and hydrogen-bonding complex, respectively at a selected wavelength. $A_{0}$ denotes the absorbance of the free BPN (or BIN) at that specific wavelength.

Fluorescent Titration Studies. Fluorescence spectra were recorded on Hitachi F-4500 and Edinburgh FS 920 spectrophotometers. The fluorescence spectra were taken using the same samples employed in the UV-vis study, i.e., transferring the same cuvette from the UVvis spectrophotometer to the fluorescence spectrophotometer for each incremental addition. The fluorescence spectra $\left(\lambda_{\mathrm{ex}}=415 \mathrm{~nm}\right.$ for BPN and $\lambda_{\mathrm{ex}}=413 \mathrm{~nm}$ for BIN) were taken as a function of saccharide concentrations.
The relationship between the measured fluorescence intensity $F$ and $\mathrm{C}_{g}$ in a selected wavelength can be expressed by $F_{0} / F-F_{0}=\Phi_{M} \epsilon_{M} /$ $\left(\Phi_{M} \epsilon_{M}-\Phi_{p} \epsilon_{p}\right)\left(1 / K_{a} C_{g}+1\right)$ where $F_{0}$ denotes the fluorescence intensity of free BPN. $\Phi_{\mathrm{M}}$ and $\Phi_{\mathrm{p}}$ are fluorescence quantum yields of the free BPN and complex, respectively, and are assumed to be constant throughout the titration. The binding constant of complex and 1:1 stoichiometry were determined by curve fitting using the nonlinear leastsquares method.

For determination of detection limit, an $\mathrm{Ar}^{+}$laser $(465.8 \mathrm{~nm}, 30$ $\mathrm{mW}$, Coherent Innova 90) was used as the excitation source. The resulting luminescence was detected by an intensified charge coupled detector (ICCD, Princeton Instrument, model 576G/1) operated at a free run mode. The fluorescence spectra $\left(\lambda_{\mathrm{ex}}=465.8 \mathrm{~nm}\right)$ of BPN $\left(1.2 \times 10^{-5} \mathrm{M}\right)$ as a function of the concentrations of octyl $\beta$-Dglucopyranoside were recorded.

Circular Dichroic Studies. The stock solutions of BIN $\left(1 \times 10^{-5}\right.$ $\mathrm{M})$ and octyl saccharides $\left(2 \times 10^{-2} \mathrm{M}\right)$ were prepared in spectroscopic grade $\mathrm{CH}_{2} \mathrm{Cl}_{2}$. The $\mathrm{BIN}$ stock solution $(2 \mathrm{~mL})$ was transferred to a $1-\mathrm{cm}$ length quartz cell, and the CD spectrum was recorded. Then 200 $\mu \mathrm{L}$ (200 equiv) of octyl saccharide solution was introduced into the same cell, and the corresponding CD spectrum was recorded.

X-ray Diffraction Analyses. The crystals were mounted on a glass fiber. Crystal data were collected on Nonius Kappa CCD or Brucker SMART CCD diffractometers installed with monochromatized Mo$K \alpha$ radiation, $\lambda=0.71073 \AA$ at $T=295 \mathrm{~K}$. All structures were solved by using the SHELXS-97 26 and refined with SHELXL- $97^{27}$ by fullmatrix least squares on $F^{2}$ values. Hydrogen atoms were fixed at calculated positions and refined using a riding mode.

Acknowledgment. We thank Professor Tashin J. Chow (Institute of Chemistry, Academia Sinica) for his help in the initial research work, Prof. Ta-Chau Chang and Mr. Jin-Yi Wu (IAMS, Academia Sinica) for CD measurements, Mr. Yi-Hung Liu (Instrumentation Center, National Taiwan University) for X-ray analyses, and National Science Council for financial support.

Supporting Information Available: Synthetic procedures, NMR, fluorescence, molecular calculations, and X-ray diffraction (PDF). These materials are available free of charge via the Internet at http://pubs.acs.org.

\section{JA039237W}

(26) Sheldrick, G. M. Acta Crystallogr. 1990, A46, 467-473.

(27) Sheldrick, G. M. SHELXL-97, Program for the Refinement of Crystal Structures; University of Göttingen: Germany, 1997. 